\title{
Radiation safety: a focus on lead aprons and thyroid shields in interventional pain management
}

\author{
Department of Anesthesiology and Pain Medicine, Konkuk University School of Medicine, Seoul, Korea \\ Bo Kyung Cheon, Cho Long Kim, Ka Ram Kim, Min Hye Kang, Jeong Ae Lim, \\ Nam Sik Woo, Ka Young Rhee, Hae Kyoung Kim, and Jae Hun Kim
}

\begin{abstract}
C-arm fluoroscopy is useful equipment in interventional pain management because it helps to guide correct needle targeting for the accurate injection and drug delivery. However, due to increased use of C-arm fluoroscopy in various pain procedures, the risk of radiation exposure is a significant concern for pain physicians. The harmful biological effects of ionizing radiation on the human body are well known. It is therefore necessary to strive to reduce radiation exposure. Lead aprons with thyroid shields are the most fundamental radiation protective devices for interventional procedures, and are very effective. However, the operator's radiation safety cannot be guaranteed because pain physicians seem to lack sufficient interest, knowledge, and awareness about radiation safety. Also, inappropriate care and use of radiation protective devices may result in a higher risk of radiation exposure. The purpose of this article was to review the literature on radiation safety with a focus on lead aprons and thyroid shields and present recommendations related to those devices during C-arm fluoroscopic-guided interventions by pain physicians. (Korean J Pain 2018; 31: 244-52)
\end{abstract}

Key Words: Fluoroscopy; Ionizing radiation; Pain management; Protective devices; Radiation exposure; Radiation protection; Thyroid gland.

\section{INTRODUCTION}

C-arm fluoroscopy is very important and useful for diagnosis and treatment in interventional pain management [1]. It ensures the target specificity of a needle for accurate injection and delivery of a drug through continuous visible $\mathrm{X}$-ray images. However, the increased use of $\mathrm{C}$-arm fluoroscopy in pain management has resulted in greater $\mathrm{ex}^{-}$ posure to ionizing radiation. Pain physicians perform the procedures close to a patient's body and the X-ray beam (the radiation source), so it is difficult to avoid unwanted exposure to scatter radiation from the patient [2-4]. Therefore, efforts to reduce radiation exposure during pain management are very important. However, in some surveys, pain physicians reported a lack of interest, awareness, and knowledge about radiation safety $[5,6]$.

There are three major factors in reducing scatter radiation doses: the time of exposure, the distance from the

Received February 20, 2018. Revised May 26, 2018. Accepted June 18, 2018.

Correspondence to: Jae Hun Kim

Department of Anesthesiology and Pain Medicine, Konkuk University School of Medicine, 120-1 Neungdong-ro, Gwangjin-gu, Seoul 05030, Korea

Tel: +82-2-2030-5749, Fax: +82-2-2030-5449, E-mail: 20110145@kuh.ac.kr

(c) This is an open-access article distributed under the terms of the Creative Commons Attribution Non-Commercial License (http:// creativecommons.org/licenses/by-nc/4.0/), which permits unrestricted non-commercial use, distribution, and reproduction in any medium, provided the original work is properly cited.

Copyright (C) The Korean Pain Society, 2018 
radiation source, and shielding from radiation. The most important among these factors is proper shielding [7]. Based on these factors, the time required to use fluoroscopy should be reduced, the physician should be positioned as far away from the radiation source as possible, and the physician should be shielded with appropriate radiation protective devices. These radiation protective devices include lead aprons, thyroid shields, radio-protective caps, gloves, lead glasses, lead barriers, and table-side or $\mathrm{pa}^{-}$ tient lead drapes. Of these, lead aprons and thyroid shields are the standard shields for the radiation safety of interventional medical staff, including pain physicians [6,8]. In this review, we discuss the basic strategies for reducing radiation exposure, as well as the proper use of lead aprons and thyroid shields in interventional pain management.

\section{MAIN BODY}

\section{Methods}

The literature review was conducted by searching database sources such as PubMed for publications in the last 10 years using the search terms "radiation safety and pain medicine", "thyroid shield", "thyroid collar", "thyroid protector", "lead aprons", and "lead equivalent aprons". Additional relevant articles were also reviewed to obtain additional information.

\section{Major sources of radiation exposure during $\mathrm{C}$-arm fluoroscopy}

There are three types of ionizing radiation exposure sources: 1) direct exposure from the primary X-ray beam, 2) scattered radiation reflected from patient's body or table, and 3) leakage from the X-ray tube [9]. There is no danger of being exposed to the primary $X$-ray beam unless the operator places his or her hand in the X-ray irradiation area during the procedure. Furthermore, because the amount of leaking $\mathrm{X}$-rays is not large, it does not substantially affect the practitioner. The major radiation exposure risk for most medical staff, including pain physicians, originates from scatter radiation [10]. The primary $\mathrm{X}$-ray beam produces scatter radiation, which interacts with the patient's body in all directions. Thus, the major factor in radiation exposure is how close the operator is to the patient during the procedure [11]. Usually, pain physicians tend to stand close to the patient and the X-ray tube. As a result, they are easily exposed to scatter radiation [2-4]. Thus, scatter radiation is a significant concern for pain physicians during $\mathrm{C}$-arm fluoroscopic procedures.

\section{Biological effects of radiation exposure}

There are two major biological effects of radiation exposure: 1) deterministic and 2) stochastic [12].

\section{1) Deterministic effects}

Deterministic effects, such as hair loss and skin burns, have a threshold value below which they do not occur [13]. Thus, adjusting the dose below the threshold dose will result in no side effects. The occurrence of opacity in the eyes and cataracts has been attributed to deterministic effects.

\section{2) Stochastic effects}

Stochastic effects (i.e., carcinogenesis and teratogenesis) have no threshold below which they do not occur [13]. Thus, because stochastic effects have no threshold, side effects may occur when the operator is exposed to radiation. In this case, as the exposure dose increases, the probability of side effects increases. It is known that radiation causes cancer; in fact, radiation-induced cancers account for $2 \%$ of all cancers. Therefore, the inappropriate use of fluoroscopy can result in high radiation exposure and can significantly increase the risk of cancer [14].

Most interventional pain procedures require fluoroscopic exposure for only short periods of time compared to other non-pain interventional procedures, such as interventional radiology, cardiology, and neurosurgery [15]. However, pain physicians who use $\mathrm{C}$-arm fluoroscopy may be at relatively high risks of radiation because of their $\mathrm{Cu}^{-}$ mulative exposure to low-dose radiation over long periods of time [16]. Low-dose radiation generally refers to radiation less than $100 \mathrm{mSv}$, such as natural radiation. Unfortunately, there is no scientific evidence for the magnitude of the direct effects of low-dose radiation on the human body. In vitro chromosomal damage due to low-dose radiation has been demonstrated, but more research is needed to determine causality with the human 
body [17].

Roguin et al. [18] reported that the risk of cancer is increased when physicians who perform interventional procedures are exposed to ionizing radiation for long periods of time. Recent evidence suggests that even protracted low-dose radiation exposure could be associated with leukemia, carotid artery atherosclerosis, and early vascular aging $[19,20]$.

The dose of radiation exposure is lifetime cumulative; a higher cumulative dose is more likely to cause cataracts, cancer, and skin injuries [16]. Thus, stochastic effects can be a major threat to medical staff involved in interventional pain management because of the cumulative effects [17].

\section{Radiation exposure of pain physicians}

When the human body is exposed to radiation, many organs of the body are affected. The organs sensitive to radiation include the ovaries and testicles, bone marrow, breasts, lens of eye, and thyroid; it is well known that the susceptibilities of the organs in the human body differ substantially [21]. The annual maximum permissible doses for medical workers published by the International Commission on Radiological Protection in 2007 are listed in Table 1 [22]. The occupational effective dose limit for radiation workers is $20 \mathrm{mSv}$ per year averaged over 5 years. For the lens of eye, the maximum exposure should not exceed $50 \mathrm{mSv}$ per year or $20 \mathrm{mSv}$ per year for more than 5 years [23].

Multiple studies have evaluated the radiation exposure of orthopedic surgeons, cardiologists, urologists, and in-

Table 1. 2007 International Commission on Radiological Protection (ICPR) Recommendations for Medical Workers

\begin{tabular}{ll}
\hline \multicolumn{1}{c}{ Exposure } & $\begin{array}{c}\text { Annual maximum } \\
\text { permissible dose (mSv) }\end{array}$ \\
\hline Whole body & 50 (20 mSv per year, \\
averaged over 5 years) & $50^{*}$ \\
Dose to the eye & 300 \\
Dose to the thyroid gland & 500 \\
Total dose to an individual organ \\
(excluding the eye)
\end{tabular}

*2011 the ICPR reduced this to $20 \mathrm{mSv}$ per year, averaged over 5 years, with no single year exceeding $50 \mathrm{mSv}$. terventional radiologists who perform a variety of visceral and peripheral angiographic procedures [24]. However, only a few reports have evaluated radiation exposure in interventional pain management. Table 2 shows the scatter radiation exposures reported by several studies at various levels of the body during fluoroscopic pain procedures.

Manchikanti et al. $[15,25]$ evaluated radiation exposure in the upper and lower part of the body in various pain procedures. The authors compared the scatter radiation exposure at the chest and groin inside and outside of aprons with or without lead shielding from the table to the floor by one physician $[15,25]$. In this study, Group I included data from individuals with lead aprons and thyroid collars, but without lead shielding from the table to the floor; Group II included data from individuals with lead aprons, thyroid collars, and lead shielding from the table to the floor on the lower part of the body. The results showed that scatter radiation exposure was higher outside the lead aprons compared to that inside the lead aprons at both chest and groin level in both groups. The scatter radiation level in Group II was $313 \mathrm{mREM}$ or $0.629 \mathrm{mREM}$ per patient outside the apron at the chest, and $176 \mathrm{mREM}$ or 0.352 mREM per patient at the groin. The doses in Group II inside the apron at the chest and groin were 0 and $13 \mathrm{mREM}$, respectively, or $0.026 \mathrm{mREM}$ per patient. These doses were lower than those in Group I. However, the scatter radiation exposure was similar in both groups at the inside of groin level (13 vs. 15 mREM total or 0.029 vs. 0.026 mREM per patient). Lead shielding from the table to the floor reduced the scatter radiation exposure for the upper part of the body as well as outside and inside the apron at all levels; however, it failed to reduce scatter radiation to the inside of the apron in the groin area. The results of this study show that the inguinal area inside a lead apron is vulnerable to radiation exposure.

Manchikanti et al. [10] also evaluated the average radiation exposure time and dose inside and outside a lead apron through a total of 1,000 patients who were undergoing various interventional pain procedures. The results showed that the exposure level was significantly less than the annual maximum permissible dose.

Botwin et al. [26-28] evaluated the radiation exposure for fluoroscopic-guided lumbar transforaminal epidural steroid injections, caudal epidural steroid injections, and lumbar discography (Table 2). The scatter radiation doses outside a lead apron at the chest were 3.98 , 0.3, and 2.367 
Table 2. Studies on Radiation Dose during C-arm Fluoroscopic Interventional Pain Procedures

\begin{tabular}{|c|c|c|c|c|c|c|c|c|c|c|c|c|}
\hline \multirow{3}{*}{$\begin{array}{c}\text { Author or, } \\
\text { year }\end{array}$} & \multirow{3}{*}{ Procedure } & \multirow{3}{*}{ Unit } & \multirow{3}{*}{$\begin{array}{l}\text { Number } \\
\text { of } \\
\text { patients }\end{array}$} & \multirow{3}{*}{$\begin{array}{c}\text { Number } \\
\text { of } \\
\text { procedures }\end{array}$} & $\begin{array}{l}\text { Neck } \\
\text { (outside) }\end{array}$ & $\begin{array}{l}\text { Neck } \\
\text { (inside) }\end{array}$ & $\begin{array}{l}\text { Chest } \\
\text { (outside) }\end{array}$ & $\begin{array}{l}\text { Chest } \\
\text { (inside) }\end{array}$ & $\begin{array}{c}\text { Groin } \\
\text { (outside) }\end{array}$ & $\begin{array}{l}\text { Groin } \\
\text { (inside) }\end{array}$ & \multirow{3}{*}{ Note } & \multirow{3}{*}{ LET } \\
\hline & & & & & \multicolumn{6}{|c|}{ Cumulative } & & \\
\hline & & & & & \multicolumn{6}{|c|}{ Per patient } & & \\
\hline \multirow{2}{*}{$\begin{array}{l}\text { Manchikanti } \\
\text { et al., } 2003\end{array}$} & $\begin{array}{l}\text { Group I } \\
\text { various }\end{array}$ & mREM & 509 & 827 & NA & 0 & $\begin{array}{l}690 \\
1.355\end{array}$ & NA & $\begin{array}{r}1152 \\
2.263\end{array}$ & $\begin{array}{l}15 \\
0.029\end{array}$ & $\begin{array}{l}\text { No lead shielding from } \\
\text { the table to the floor }\end{array}$ & $0.5 \mathrm{~mm}$ \\
\hline & $\begin{array}{c}\text { Group II } \\
\text { various }\end{array}$ & mREM & 500 & 865 & NA & 0 & $\begin{array}{l}313 \\
0.626\end{array}$ & 0 & $\begin{array}{l}176 \\
0.352\end{array}$ & $\begin{array}{l}13 \\
0.026\end{array}$ & $\begin{array}{l}\text { Lead shielding from the } \\
\text { table to the floor }\end{array}$ & $0.5 \mathrm{~mm}$ \\
\hline \multirow[t]{2}{*}{$\begin{array}{l}\text { Kim et al., } \\
2010\end{array}$} & \multirow[t]{2}{*}{ Various } & mREM & Operator & 505 & $\begin{array}{l}2032 \\
4.023^{\star *}\end{array}$ & NA & NA & $\begin{array}{l}108 \\
0.21^{* *}\end{array}$ & $\begin{array}{r}1292^{\star} \\
2.56^{\star \star}\end{array}$ & NA & \multirow{5}{*}{$\begin{array}{l}\text { Predicted annual radia- } \\
\text { tion dose calculated } \\
\text { from dosimeter }\end{array}$} & \multirow[t]{2}{*}{$0.5 \mathrm{~mm}$} \\
\hline & & & Assistant & & $\begin{array}{l}572 \\
1.13^{\star \star}\end{array}$ & & & $\begin{array}{l}82 \\
0.16^{\star *}\end{array}$ & $\begin{array}{l}504^{\star} \\
0.99^{\star *}\end{array}$ & & & \\
\hline $\begin{array}{l}\text { Botwin et al., } \\
2001\end{array}$ & Caudal ESI & mREM & 100 & 100 & NA & NA & $\begin{array}{l}398 \\
3.98\end{array}$ & $\begin{array}{l}15 \\
0.15\end{array}$ & NA & NA & & $0.55 \mathrm{~mm}$ \\
\hline $\begin{array}{l}\text { Botwin et al., } \\
2002\end{array}$ & $\begin{array}{l}\text { Lumbar } \\
\text { TFESI }\end{array}$ & mREM & 100 & 100 & NA & NA & $\begin{array}{l}30 \\
0.3\end{array}$ & 0 & NA & NA & & $0.55 \mathrm{~mm}$ \\
\hline $\begin{array}{l}\text { Botwin et al., } \\
2003\end{array}$ & $\begin{array}{l}\text { Lumbar } \\
\text { discography }\end{array}$ & mREM & 37 & 106 & NA & NA & $\begin{array}{l}251 \\
2.367\end{array}$ & $\begin{array}{l}10 \\
0.27\end{array}$ & NA & NA & & $0.55 \mathrm{~mm}$ \\
\hline
\end{tabular}

mREM per patient during caudal epidural steroid injections, lumbar transforaminal epidural steroid injections, and lumbar discography, respectively. Collectively, the results of these three studies demonstrate that radiation exposure to physicians performing fluoroscopic-guided pain procedures is well within safety limits when the proper techniques are followed.

Kim et al. [3] estimated the probable annual level of radiation exposure for $\mathrm{C}$-arm fluoroscopic-guided interventional pain procedures by a primary operator and an assistant over a 3-month period (Table 2). The results showed that the predicted annual radiation dose calculated from the three measurements were all within the permissible radiation doses. The radiation doses were measured by a dosimeter under a lead apron, over a thyroid collar, and on the leg; all doses were higher for the operator than for the assistant. The dosimeter under the apron was used to measure whole-body exposure. There were no significant differences when comparing doses over the thyroid collar or on the leg for the whole-body exposure levels of the operator and assistant because they both wore lead aprons to protect the whole body. It was assumed that the assistant normally stood $1 \mathrm{~m}$ further away from the X-ray beam than the operator; the exposure doses over the thyroid collar and on the leg were greater for the operator than for the assistant, and radiation exposure is inversely proportional to the square of the distance [3]. These results indicate that the distance from the radiation source is an important factor for radiation safety.

In all of the described studies, radiation exposure during pain management was within safety limits when lead aprons and thyroid shields were used. However, stochastic effects should not be overlooked. Thus, it is recommended to reduce radiation exposure as much as possible.

\section{Efforts to reduce scatter radiation}

A basic concept to reduce radiation exposure is "as low as reasonably achievable" (ALARA) [29]. Based on this concept, the three major factors to reduce occupational exposure to scatter radiation are the time of exposure, the distance to radiation, and shielding from radiation [7]. Therefore, procedures first should be performed by experienced pain physicians in order to decrease the procedure time and thus minimize radiation exposure time. As mentioned previously, radiation exposure is inversely proportional to the square of the distance from the radiation source reflected from the patient's body. For example, a distance twice that of the original distance results in a fourfold decreased radiation exposure. The scatter exposure level from a patient who is $1 \mathrm{~m}$ away is approximately $0.1 \%$ of the patient's entrance skin exposure [30]. 
The radiation dose depends on the type of interventional pain procedure, the patient's size, the equipment, the technique, and many other factors [10]. Lumbar medial branch blocks, lumbar epidural blocks, and caudal epidural blocks have relatively short procedure times; however, the procedure times are longer for sacroiliac joint injections, epidural adhesiolysis, sympathetic blocks, and spinal cord stimulation. If an individual has severe degenerative changes, spondylolisthesis, osteoporosis, or previous spinal surgery (depending on the spinal pathology), anatomical landmarks may disappear, thus affecting the screening time and also increasing the procedure time.

Dose area product is a unit that may be used instead of the effective dose; this number is automatically recorded by image intensifiers. Hanu-Cernat et al. [31] reported that the dose area product is increased for patients with greater body mass. Therefore, efforts are needed to adhere to the ALARA principle for dose exposure, regardless of the occupational dose limits.

\section{Radiation protective devices}

Appropriate shielding is the most important factor in protecting individuals from radiation exposure. There are three types of shielding: 1) structural shielding, 2) equipment-mounted shielding, and 3) personal protective devices.

Structural shielding is embedded into the walls of the procedural suite. In addition, mobile, transparent, and leaded acrylic shields offer protection from direct exposure but are less effective at protecting against scatter radiation.

Equipment-mounted shielding includes leaded drapes and leaded acrylic shields suspended from the fluoroscopy table or scanner.

Personal protective devices include lead aprons, thyroid shields, lead glasses, caps, and gloves [29]. All personnel who perform $\mathrm{C}$-arm fluoroscopic-guided procedures should wear personal radiation shielding devices to protect themselves. Personal protective devices are made of lead composite or lighter lead-free materials that attenuate scatter radiation using various designs.

\section{1) Lead aprons}

Lead aprons are the primary radiation protective garments used by personnel during fluoroscopy. The radiation protection provided by a lead apron is approximately the same as $0.25-$ to $1-\mathrm{mm}$ thick lead. An apron with $0.5-\mathrm{mm}$ thickness can attenuate approximately $90 \%$ or more of the scatter radiation. Lead glasses with $0.5-$ or $0.75-\mathrm{mm}$ thickness can reduce more than $95 \%$ of scatter radiation [32]. According to studies conducted in Korea, lead aprons, thyroid shields, and lead glasses are worn by approximately $93-100 \%, 81-100 \%$, and $38-40 \%$ of operators, respectively $[5,6,33]$. However, the lens of the eye is the most radiation-sensitive part of the body; therefore, wearing lead glasses is essential.

Lead aprons should have at least $0.25-\mathrm{mm}$ lead-equivalent thickness on the back and front. Wraparound-type aprons are designed with $0.25+0.25 \mathrm{~mm}$ lead-equivalent thickness in the front (0.5 mm total) [34]. There are several different designs available, including aprons with front coverage only, aprons that wrap around the body, and a vest and kilt combination. If the back is exposed to the radiation source and the patient during the procedure, wraparound aprons or vests with kilts are suitable [32].

Regardless of the design, it is most important that the garment fits properly at the neckline and armhole [32]. Large gaps could result in the increased exposure of breast tissue, which is especially important for female staff [35]. A large cohort study and survey found an increased prevalence of breast cancer among female radiation technologists. Another study showed a significantly increased risk of breast cancer for female radiologic technologists who were exposed to daily low-dose radiation for several years, which potentially resulted in significant cumulative exposures. A third study reported a 1.9-fold increased prevalence of cancer and a 2.9-fold increased prevalence of breast cancer in female orthopedic surgeons compared with American women of similar ages and races [36]. Thus, aprons of appropriate size and proper fit should be provided to each operator.

The long-term use of heavy radiation-protective garments is associated with musculoskeletal problems and fatigue in interventional physicians [37,38]. Surveys of interventional cardiologists and radiologists indicate evidence of a relationship between the use of lead aprons and spine problems $[39,40]$. A standard lead apron weighs approximately $7 \mathrm{~kg}$, which could cause the development of back problems [41]. Conventional lead aprons are heavy, but 
newer aprons are made of lighter-weight protective materials, including barium, tungsten, tin, and antimony. These aprons are $20-40 \%$ lighter than standard lead aprons ( -4 $\mathrm{kg}$ ) and have a lead equivalent weight effect similar to lead aprons.

The X-ray transmittance for $70-100 \mathrm{kVp}$ was $0.5-5 \%$ when using a $0.5-\mathrm{mm}$ lead apron and $0.6-6.8 \%$ when using a lead composite or lead-free apron with $0.5-$ mm lead equivalent thickness [41]. Lighter materials are under development. For example, aprons made from lead-free bismuth have shown excellent shielding in a phantom study. However, for an operator who performs procedures beside a patient, the shielding effect is less than when wearing a lead apron [42]. In addition, the vest and quilt design reduces the burden on the spine, as compared with a one-piece apron, by distributing the weight concentrated on the shoulders and back to the shoulders and hips.

The shielding materials inside protective garments may suffer damage after long-term use, such as cracks or holes, which may not be visible $[33,37]$. Therefore, it is necessary to regularly inspect aprons and other radiation protective garments every year to determine the degree of damage [43]. Visual and tactile tests can be performed; in case of doubt, a fluoroscopic image can be taken to find uniformity or holes [34]. A survey on the degree of damage of lead aprons used during pain management in a general hospital operating room showed that the most common site of damage was the waist of the apron (51\%), followed by the lower part of the apron (33\%) [44]. An apron should always be handled carefully and kept hanging when not in use.

\section{2) Thyroid shields}

The thyroid gland should be protected because it is vulnerable to scatter radiation [9]. Thyroid shields are the best way to minimize the risk of thyroid cancer from radiation exposure during procedures. The annual maximum permissible dose recommended to the thyroid is $300 \mathrm{mSv}$ [45]. A thyroid shield can reduce the effective dose by 2.5 times and the total exposure by almost 50\% [46]. Therefore, thyroid shields should have at least $0.5-\mathrm{mm}$ lead equivalent thickness for neck and thyroid protection.

Thyroid shields provide very effective protection to the thyroid, but they do have limitations from weight and movement [47]. For example, some surgeons wear thyroid shields loosely or not at all because they are uncomfortable when worn tightly and properly $[33,45]$. However, despite this discomfort, tightening the thyroid shield has a greater effect on the thyroid gland [7].

One study investigated the most effective thyroid shields for thyroid protection using simulations during spinal surgery [48]. In the lead-shield group, radiation doses were measured with the shield worn tightly, worn loosely, and worn loosely with a bismuth masking reagent. Wearing the shield tight against the throat and wearing it loosely with a bismuth masking reagent led to lower radiation $\mathrm{ex}^{-}$ posure levels compared with simply wearing the shield loosely $(P \leq 0.001)$. In the lead-equivalent shield group, doses were measured for the same three conditions. Lower scattered radiation doses were delivered to the thyroid in the lead-equivalent thyroid shield group compared with the lead thyroid shield group $(P \leq 0.001)$. The best way to reduce scattered radiation exposure to the thyroid is by wearing the thyroid shield tightly or by wearing it loosely in combination with a bismuth masking reagent [48]. However, bismuth masking is somewhat expensive.

Radiation exposure is a cause of thyroid cancer, and the dose and age of exposure to the thyroid are major risk factors for thyroid cancer [49]. The precise risk of scattered radiation to the thyroid is still unknown. A cumulative dose of $65 \mu \mathrm{Sv}$ per operation has been reported to increase the long-term risk of thyroid cancer. The risk of radiation-induced thyroid cancer is significantly reduced with age, and the risk is less critical at age 40 years and older [32]. However, considering the stochastic effects, protection of the thyroid gland is essential because it can be highly exposed to scatter radiation if a thyroid shield is not worn. A thyroid shield should also be checked for damage with an annual inspection, like that for aprons [43].

\section{Radiation safety education}

Radiation safety education is important to protect patients and medical staff. Despite the increasing use of fluoroscopy for diagnosis and treatment in interventional pain management, appropriate education and training programs on radiation safety are lacking. There is no formal requirement for the education of pain physicians in Korea within pain fellowship programs. However, a radiation safety educational program for orthopedic surgery residents led to decreased radiation exposure in residents and patients 
[50], and an online course regarding the safe use of fluoroscopy for radiology residents decreased patient doses without affecting diagnostic quality [51].

Several surveys have investigated radiation safety knowledge and efforts to reduce exposure [5,6,52,53]. Korean surveys in 2011 and 2016 reported that pain physicians' knowledge about radiation safety is lacking, with $61 \%$ of respondents never having received radiation safety education. Even among those who received education, their efforts to reduce radiation exposure did not differ significantly from those of physicians who never received radiation education. Thus, there is a gap between the education and practice of radiation safety [5].

A survey of orthopedic surgeons' knowledge on radiation protective measures and preferred methods indicated that most surgeons were lacking the required technical background for C-arm fluoroscopy [52]. Another study evaluated whether real-time coaching feedback on scattered radiation dose monitoring during pain treatment can reduce the scattered dose received by the physician. However, procedures with real-time monitoring of the scattered dose profile did not have significantly different exposure levels than procedures without monitoring, presumably because of the shorter procedure time without monitoring. However, real-time coaching on the appropriate position for dose reduction while monitoring the scattered radiation dose increased the physician's awareness of the scattered radiation, reducing the radiation dose to the pain physician by half [54].

Currently, radiation safety education is not mandatory for a pain specialist qualification in Korea. However, radiation safety education is necessary to improve awareness and knowledge of radiation safety. It is also important to coach pain specialist trainees on good habits regarding radiation safety.

\section{CONCLUSIONS}

The ALARA principles of time, distance, and shielding are basic strategies to reduce radiation exposure. Lead aprons and thyroid shields are the most frequently used personal radiation protective devices, but their importance is often overlooked. Protective devices that are used inappropriately or are not properly cared for increase the risk of radiation exposure. The use of well-fitting and lightweight lead aprons and thyroid shields, as well as regular annual inspections, are effective and important ways to use personal protective equipment. Both proper education and training on the appropriate use of radiation protective devices and equipment should be mandatory to reduce radiation exposure in practice.

\section{REFERENCES}

1. Kim S, Shin JH, Lee JW, Kang HS, Lee GY, Ahn JM. Factors affecting radiation exposure during lumbar epidural steroid injection: a prospective study in 759 patients. Korean $\mathrm{J}$ Radiol 2016; 17: 405-12.

2. Linet MS, Kim KP, Miller DL, Kleinerman RA, Simon SL, Berrington de Gonzalez A. Historical review of occupational exposures and cancer risks in medical radiation workers. Radiat Res 2010; 174: 793-808.

3. Kim TW, Jung JH, Jeon HJ, Yoon KB, Yoon DM. Radiation exposure to physicians during interventional pain procedures. Korean J Pain 2010; 23: 24-7.

4. Tsapaki V, Kottou S, Vano E, Parviainen T, Padovani R, Dowling $A$, et al. Correlation of patient and staff doses in interventional cardiology. Radiat Prot Dosimetry 2005; 117 : 26-9.

5. Kim TH, Hong SW, Woo NS, Kim HK, Kim JH. The radiation safety education and the pain physicians' efforts to reduce radiation exposure. Korean J Pain 2017; 30: 104-15.

6. Park PE, Park JM, Kang JE, Cho JH, Cho SJ, Kim JH, et al. Radiation safety and education in the applicants of the final test for the expert of pain medicine. Korean J Pain 2012; 25: $16-21$.

7. Fishman SM, Smith H, Meleger A, Seibert JA. Radiation safety in pain medicine. Reg Anesth Pain Med 2002; 27 : 296-305.

8. Kim C, Vasaiwala S, Haque F, Pratap K, Vidovich MI. Radiation safety among cardiology fellows. Am J Cardiol 2010; 106: 125-8.

9. Dagal A. Radiation safety for anesthesiologists. Curr Opin Anaesthesiol 2011; 24: 445-50.

10. Manchikanti L, Cash KA, Moss TL, Pampati V. Radiation exposure to the physician in interventional pain management. Pain Physician 2002; 5: 385-93.

11. Le Heron J, Padovani R, Smith I, Czarwinski R. Radiation protection of medical staff. Eur J Radiol 2010; 76: 20-3.

12. Blakely EA. Biological effects of cosmic radiation: deterministic and stochastic. Health Phys 2000; 79: 495-506.

13. Shortt CP, Fanning NF, Malone L, Thornton J, Brennan P, Lee MJ. Thyroid dose during neurointerventional procedures: does lead shielding reduce the dose? Cardiovasc Intervent Radiol 2007; 30: 922-7.

14. Sont WN, Zielinski JM, Ashmore JP, Jiang H, Krewski D, Fair $\mathrm{ME}$, et al. First analysis of cancer incidence and occupational 
radiation exposure based on the National Dose Registry of Canada. Am J Epidemiol 2001; 153: 309-18.

15. Manchikanti L, Cash KA, Moss TL, Pampati V. Effectiveness of protective measures in reducing risk of radiation exposure in interventional pain management: a prospective evaluation. Pain Physician 2003; 6: 301-5.

16. Broadman LM, Navalgund YA, Hawkinberry DW 2nd. Radiation risk management during fluoroscopy for interventional pain medicine physicians. Curr Pain Headache Rep 2004; 8: 49-55.

17. Zhou Y, Singh N, Abdi S, Wu J, Crawford J, Furgang FA. Fluoroscopy radiation safety for spine interventional pain procedures in university teaching hospitals. Pain Physician 2005; 8: 49-53.

18. Roguin A, Goldstein J, Bar O, Goldstein JA. Brain and neck tumors among physicians performing interventional procedures. Am J Cardiol 2013; 111: 1368-72.

19. Leuraud K, Richardson DB, Cardis E, Daniels RD, Gillies M, O'Hagan JA, et al. lonising radiation and risk of death from leukaemia and lymphoma in radiation-monitored workers (INWORKS): an international cohort study. Lancet Haematol 2015; 2: e276-81.

20. Andreassi MG, Piccaluga E, Gargani L, Sabatino L, Borghini A, Faita F, et al. Subclinical carotid atherosclerosis and early vascular aging from long-term low-dose ionizing radiation exposure: a genetic, telomere, and vascular ultrasound study in cardiac catheterization laboratory staff. JACC Cardiovasc Interv 2015; 8: 616-27.

21. Biswas D, Bible JE, Bohan M, Simpson AK, Whang PG, Grauer JN. Radiation exposure from musculoskeletal computerized tomographic scans. J Bone Joint Surg Am 2009; 91: 1882-9.

22. Stewart FA, Akleyev AV, Hauer-Jensen M, Hendry JH, Kleiman NJ, Macvittie TJ, et al. ICRP publication 118: ICRP statement on tissue reactions and early and late effects of radiation in normal tissues and organs---threshold doses for tissue reactions in a radiation protection context. Ann ICRP 2012; 41: 1-322.

23. International Commission on Radiological Protection (ICRP). Statement on tissue reactions. Approved by the commission on April 21, 2011. ICRP ref 4825-3093-1464. Ottawa, International Commission on Radiological Protection. 2011.

24. Mahesh M. Fluoroscopy: patient radiation exposure issues. Radiographics 2001; 21: 1033-45.

25. Manchikanti L, Cash KA, Moss TL, Rivera J, Pampati V. Risk of whole body radiation exposure and protective measures in fluoroscopically guided interventional techniques: a prospective evaluation. BMC Anesthesiol 2003; 3: 2.

26. Botwin KP, Freeman ED, Gruber RD, Torres-Rames FM, Bouchtas CG, Sanelli JT, et al. Radiation exposure to the physician performing fluoroscopically guided caudal epidural steroid injections. Pain Physician 2001; 4: 343-8.
27. Botwin KP, Thomas S, Gruber RD, Torres FM, Bouchlas CC, Rittenberg JJ, et al. Radiation exposure of the spinal interventionalist performing fluoroscopically guided lumbar transforaminal epidural steroid injections. Arch Phys Med Rehabil 2002; 83: 697-701.

28. Botwin KP, Fuoco GS, Torres FM, Gruber RD, Bouchlas CC, Castellanos R, et al. Radiation exposure to the spinal interventionalist performing lumbar discography. Pain Physician 2003; 6: 295-300.

29. Wang RR, Kumar AH, Tanaka P, Macario A. Occupational radiation exposure of anesthesia providers: a summary of key learning points and resident-led radiation safety projects. Semin Cardiothorac Vasc Anesth 2017; 21: 165-71.

30. Statkiewicz-Sherer MA, Visconti PJ, Ritenour ER. Radiation protection in medical radiography. 3rd ed. St. Louis (MO), Mosby. 1998.

31. Hanu-Cernat DE, Duarte R, Raphael JH, Mutagi H, Kapur $S$, Senthil L. Type of interventional pain procedure, body weight, and presence of spinal pathology are determinants of the level of radiation exposure for fluoroscopically guided pain procedures. Pain Pract 2012; 12: 434-9.

32. Schueler BA. Operator shielding: how and why. Tech Vasc Interv Radiol 2010; 13: 167-71.

33. Baek SW, Ryu JS, Jung CH, Lee JH, Kwon WK, Woo NS, et al. A randomized controlled trial about the levels of radiation exposure depends on the use of collimation $\mathrm{C}$-arm fluoroscopic-guided medial branch block. Korean J Pain 2013; 26: 148-53.

34. Srinivasan D, Than KD, Wang AC, La Marca F, Wang PI, Schermerhorn TC, et al. Radiation safety and spine surgery: systematic review of exposure limits and methods to minimize radiation exposure. World Neurosurg 2014; 82: 1337-43.

35. National Council on Radiation Protection and Measurements. Radiation dose management for fluoroscopically-guided interventional medical procedures. NCRP report 168. Bethesda (MD), National Council on Radiation Protection and Measurements. 2012.

36. Chou LB, Cox CA, Tung JJ, Harris AH, Brooks-Terrell D, Sieh $W$. Prevalence of cancer in female orthopaedic surgeons in the United States. J Bone Joint Surg Am 2010; 92: 240-4.

37. Klein LW, Miller DL, Balter S, Laskey W, Haines D, Norbash $A$, et al. Occupational health hazards in the interventional laboratory time for a safer environment: time for a safer environment. J Vasc Interv Radiol 2009; 20: 147-52.

38. Alexandre D, Prieto M, Beaumont F, Taiar R, Polidori G. Wearing lead aprons in surgical operating rooms: ergonomic injuries evidenced by infrared thermography. J Surg Res 2017; 209: 227-33.

39. Klein LW, Tra Y, Garratt KN, Powell W, Lopez-Cruz G, Chambers $C$, et al. Occupational health hazards of interventional cardiologists in the current decade: results of the 2014 SCAl membership survey. Catheter Cardiovasc 
Interv 2015; 86: 913-24.

40. Dixon RG, Khiatani V, Statler JD, Walser EM, Midia M, Miller $\mathrm{DL}$, et al. Society of Interventional Radiology: Occupational Back and Neck Pain and the Interventional Radiologist. J Vasc Interv Radiol 2017; 28: 195-9.

41. Papadopoulos N, Papaefstathiou C, Kaplanis PA, Menikou G, Kokona G, Kaolis D, et al. Comparison of lead-free and conventional $X$-ray aprons for diagnostic radiology. World congress on medical physics and biomedical engineering. Munich, Germany. New York (NY), Springer. 2009. pp 544-6.

42. Sawdy JM, Gocha MD, Olshove V, Chisolm JL, Hill SL, Phillips A, et al. Radiation protection during hybrid procedures: innovation creates new challenges. J Invasive Cardiol 2009; 21: 437-40.

43. Badawy MK, Deb P, Chan R, Farouque O. A review of radiation protection solutions for the staff in the cardiac catheterisation laboratory. Heart Lung Circ 2016; 25: $961-7$.

44. Ryu JS, Baek SW, Jung CH, Cho SJ, Jung EG, Kim HK, et al. The survey about the degree of damage of radiation-protective shields in operation room. Korean $J$ Pain 2013; 26: 142-7.

45. Devalia KL, Peter VK, Madanur MA, Braithwaite IJ. Exposure of the thyroid to radiation during routine orthopaedic procedures. Acta Orthop Belg 2006; 72: 615-20.

46. Müller LP, Suffner J, Wenda K, Mohr W, Rommens PM. Radiation exposure to the hands and the thyroid of the surgeon during intramedullary nailing. Injury 1998; 29: 461-8.
47. Health risks from exposure to low levels of lonizing radiation: BEIR VII, phase I, letter report. Washington, D.C., National Academies Press. 1998.

48. Lee SY, Min E, Bae J, Chung CY, Lee KM, Kwon SS, et al. Types and arrangement of thyroid shields to reduce exposure of surgeons to ionizing radiation during intraoperative use of C-arm fluoroscopy. Spine 2013; 38: 2108-12.

49. Iglesias ML, Schmidt A, Ghuzlan AA, Lacroix L, Vathaire F, Chevillard S, et al. Radiation exposure and thyroid cancer: a review. Arch Endocrinol Metab 2017; 61: 180-7.

50. Gendelberg D, Hennrikus W, Slough J, Armstrong D, King S. A radiation safety training program results in reduced radiation exposure for orthopaedic residents using the mini C-arm. Clin Orthop Relat Res 2016; 474: 580-4.

51. Frederick-Dyer KC, Faulkner AR, Chang TT, Heidel RE, Pasciak AS. Online training on the safe use of fluoroscopy can result in a significant decrease in patient dose. Acad Radiol 2013; 20: 1272-7.

52. Tunçer N, Kuyucu E, Sayar Ş, Polat G, Erdil İ, Tuncay İ. Orthopedic surgeons' knowledge regarding risk of radiation exposition: a survey analysis. SICOT J 2017; 3: 29.

53. Lynskey GE 3rd, Powell DK, Dixon RG, Silberzweig JE. Radiation protection in interventional radiology: survey results of attitudes and use. J Vasc Interv Radiol 2013; 24: 1547-1551.e3.

54. Slegers AS, Gültuna I, Aukes JA, van Gorp EJ, Blommers FM, Niehof SP, et al. Coaching reduced the radiation dose of pain physicians by half during interventional procedures. Pain Pract 2015; 15: 400-6. 